\title{
Von Hippel-Lindau's disease presenting at an early age
}

\author{
P. J. BOURDILLON ${ }^{1}$ AND R. C. HICKMAN ${ }^{2}$ \\ From the Department of Neurology and Neurosurgery, Middlesex Hospital, London
}

The familial incidence of haemangiomatosis of the central nervous system, von Hippel-Lindau's disease, has been recorded by a number of authors. Fuchs (1882) was the first to describe a retinal lesion in which a peripheral red spot was fed by a dilated and tortuous retinal artery and vein. He described this as an arteriovenous aneurysm of the retina. Treacher Collins (1894) stated that the lesion was made up of numerous thin-walled blood vessels enclosing cystic spaces. He also noted the inherited nature of the disease, having dissected three eyes from a brother and sister with similar lesions. Von Hippel (1904) followed the natural history in one patient who eventually underwent enucleation of the affected eye. He named the disease angiomatosis retinae and noted some of the complications, including retinitis proliferans which might proceed to detachment of the retina, secondary glaucoma due to haemorrhage, and cataract. Lindau (1926) described two cases of haemangioblastoma of the cerebellum, which were associated with angiomatosis retinae. He found that the histological appearances of the cerebellar tumours and of the retinal angiomata were identical.

The present paper records a family affected by Lindau's disease showing some unusual features of the condition.

\section{THE AFFECTED FAMILY}

GENERATION I Few details of the medical history of this generation are available. Case $\mathbf{I} 2$ died of cancer.

GENERATION II Case II1 died of coronoary thrombosis at the age of 50. Case II2 died of cancer at the age of 60 . Case II3 died of an accident at the age of 51. There was no history of neurological disease in these three persons.

Case II4 suffered from headaches for five years before her admission to hospital at the age of 40 . No details are available, other than that she died shortly after exploration of the posterior fossa. 52.

Case II5 died of carcinoma of the breast at the age of

Present address: ' ${ }^{P}$. J. Bourdillon, London Chest Hospital, London, ${ }^{2}$ R. C. Hickman, Brompton Hospital, London, S.W.3.

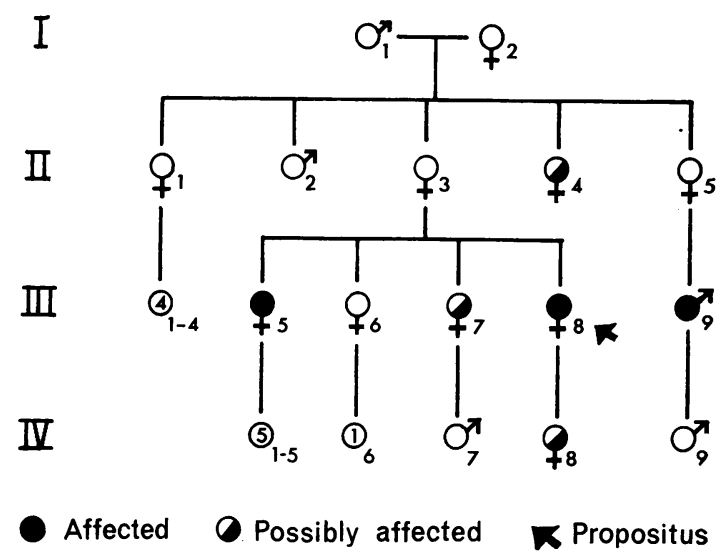

FIG. 1. Pedigree of the affected faculty.

GENERATION III Cases III1-4 are all alive and well, and there is no history of neurological disease.

Case III5 (patient of Professor Brodie Hughes, Queen Elizabeth Hospital, Birmingham, No. 439495) at the age of 31 presented with failing vision. This started during her third pregnancy, four and a half years previously. She has had five pregnancies; all but the first were complicated by vomiting. Examination showed that the visual acuity in the right eye was 'perception of light' only but it was normal in the left eye. The fundus of the right eye showed an angioma in the upper temporal zone and a white retinal scar below the optic disc. The left fundus was normal. The red cell count was normal, as was a right carotid arteriogram. She has now lost all vision in the right eye, but is otherwise well.

Case III6 is alive and well.

Case III7 (patient of Dr. Bruce Hendrick) presented at the age of 25 with sudden loss of vision a few days after the normal delivery of a healthy child. The pregnancy had been complicated by prolonged vomiting. During the previous four years she had noticed a swelling in the left temporal fossa. On examination she was found to be completely blind in the right eye, and to have only a small field of vision in the left eye. Radiological examination of the skull suggested the presence of a large meningioma arising from the left frontal bone and extending 
into the left orbit. At operation a large tumour of the left frontal region was found and excised. The tumour weighed $56 \mathrm{~g}$., and it had the histological appearances of a meningothelial type of meningioma with malignant change. The tumour recurred four years later and a further operation was performed. This was followed by radiotherapy. In 1964, four years later, she had a further course of radiotherapy. She is now totally blind.

Case III8 (patient of Professor R. W. Gilliatt and Mr. John Andrew, Middlesex Hospital, No. K 84697) was first seen during her second pregnancy at the age of 25 , when she was suffering from hyperemesis gravidarum. Her first pregnancy had been normal throughout, but during the fourth week of her second pregnancy, vomiting began and, seven days later, her weight had fallen from $45 \mathrm{~kg}$. to $34 \mathrm{~kg}$. The dehydration required intravenous transfusion for correction. No abnormal neurological signs were found on examination. The lumbar cerebrospinal fluid on two occasions showed the protein content to be $275 \mathrm{mg}$. per $100 \mathrm{ml}$. and $180 \mathrm{mg}$. per $100 \mathrm{ml}$. with a normal pressure. The vomiting persisted until the twentieth week when the pregnancy was terminated by Mr. R. Lloyd-Jones.

Six months later the patient was readmitted for a lumbar air encephalogram which showed herniation of the cerebellar tonsils into the upper cervical canal. The protein content of the cerebrospinal fluid was again raised (200 mg. per $100 \mathrm{ml}$.). Six months later another lumbar puncture was performed and the protein content of the cerebrospinal fluid was still found to be raised at $288 \mathrm{mg}$. per $100 \mathrm{ml}$. In the following year her third pregnancy had to be terminated because of severe vomiting. She subsequently underwent voluntary sterilization. She was then well until the age of 30 , when she began to experience increasingly severe morning headache and neck stiffness. There was no vomiting, visual disturbance, or disturbance of gait. She was readmitted to hospital and was found to have bilateral chronic papilloedema with some retinal haemorrhages. Her visual acuity was normal. Skull radiographs showed thinning of the posterior clinoid processes. Urine analysis was normal and the haemoglobin was 11.7 g. per $100 \mathrm{ml}$. Ventriculography showed a severe degree of internal hydrocephalus and displacement of the fourth ventricle anteriorly. There was thought to be some deformity in the region of the foramen of Magendie. Exploration of the posterior fossa showed that the obstruction was due to a small haemangioblastoma about the size of a pea, which had produced a cyst excavating the obex of the medulla and the upper limit of the cervical cord, and also obliterated the foramen of Magendie. The cerebellar tonsils were herniated about $2 \mathrm{~cm}$. into the cervical canal. The cyst was emptied and the tumour excised. A second small vascular tumour was found on the superior surface of the left cerebellar hemisphere, which also was shown histologically to be an haemangioblastoma. The patient made a good recovery.

Case III9 (patient of the late Professor Sir Hugh Cairns, Radcliffe Infirmary, No. 99328/49, and Mr. E. F. King, Moorfields Eye Hospital, No. J 31166) presented at the age of 9 with a three-month history of headache and vomiting and a three-week history of strabismus and double vision. An optician found that the child had bilateral papilloedema so he was referred to hospital. On examination the visual acuity in each eye was 6/6. A mild right external rectus paresis and facial weakness were found. There was also generalized muscle hypotonia, ataxia of the right leg and unsteadiness of gait. A decompression of the posterior fossa was performed and three months later an haemangioblastoma, $6 \mathrm{~cm}$. in its widest diameter, was removed from the right cerebellum. He then remained well for nine years, when, at the age of 18 , he lost the sight of his right eye, so that he could barely perceive light. The cause for this was a subtotal retinal detachment. In the fundus of the left eye an angioma was seen below the optic disc. This angioma was treated by diathermy coagulation on seven occasions during the next 18 months. The visual acuity in the left eye remained at $6 / 6$ for a further 18 months, when he suddenly lost the sight in that eye. Since then he has remained well, although he is totally blind.

GENERATION IV Cases IV1-7 ${ }^{1}$ are all well with no history of neurological disease.

Case IV8 (patient of Mr. John Andrew, Middlesex Hospital, No. G 71510) at the age of 10 presented with an 11-month history of a high-pitched pulsating left tinnitus and slight deafness in the left ear. The tinnitus was intermittent at first but soon became continuous. Five months later she experienced some headache for a few days, while transient episodes of vertical nystagmus occurred for about a week. She had no past history of ear disease. On examination she had early papilloedema, horizontal nystagmus on left lateral gaze, a moderate left conductive deafness, and ataxia of stance and gait. There was a chronic infection of the left nasal cavity. The left ear-drum was dark, lustreless and retracted. Its movement was impaired. Skull radiographs showed an area of destruction of the petrous portion of the left temporal bone around the internal auditory meatus, which extended to the anterior border of the jugular foramen. The haemoglobin was $13 \cdot 1 \mathrm{~g}$. per $100 \mathrm{ml}$. and urine analysis showed no abnormality. Carotid angiography showed that the lateral ventricles were normal in size, whilst vertebral angiography showed that the left superior cerebellar artery was displaced medially.

When the left cerebellopontine angle was explored, an area of bluish, discoloured dura mater was seen elevated $1 \mathrm{~cm}$. from the petrous bone and extending from the jugular foramen inferiorly to just posterior to the internal auditory meatus superiorly. About $4 \mathrm{ml}$. of altered blood was found beneath this dura and was overlying an extensive area of honeycombed bone destruction. The bone preserved looked thickened and sclerotic. No tumour tissue was present. Post-operatively she made a good recovery and the papilloedema partially cleared. It was suspected that the collection of blood had been associated with an haemorrhagic incident six months previously, when she developed headache.

Case IV9 is alive and well.

${ }^{1}$ Case IV7, at the age of 11 , has recently been admitted to Toronto Western Hospital, under the care of Dr. Bruce Hendrick, with blurring of vision. 


\section{DISCUSSION}

For the diagnosis of von Hippel-Lindau's disease there must be either a family history of retinal and cerebellar angiomata or a retinal and cerebellar angioma must be present in the same patient. Among the many associated lesions are haemangioblastomata of the spinal cord, pancreatic cysts, renal and epididymal cysts, and renal carcinomata.

The mode of inheritance is that of an autosomal dominant gene. Thus half the children of an affected heterozygous parent would be expected to carry the gene. If, in a large series, less than half the members of a family are affected, as Nicol (1957) and Christoferson, Gustafson, and Petersen (1961) found in their series, the expression of this gene is incomplete. On the other hand Larson (1957) and Melmon and Rosen (1964) believe that with the passage of time and a vigorous screening programme many more lesions would become apparent. The phenomenon of genetic anticipation (the appearance of clinical disease at an earlier age in successive generations), which Bird and Krynauw (1953), Melmon and Rosen (1964), and Yin and Chang (1965) reported in the families they described, is likewise striking in ours.

A review of the literature has shown that while many authors, including Bergstrand, Olivecrona, and Tönnis (1936), Bray and Davies (1949), Cramer and Kimsey (1952), Silver and Hennigar (1952), Jefferson (1953), Borck and Tönnis (1955), Krayenbühl and Yasargil (1958), Stein, Schilp, and Whitfield (1960), and Isfort and Sunder-Plassmann (1965), have described cerebellar haemangioblastomata in childhood, Lindau's disease satisfying the criteria mentioned above has not previously been recorded in prepubertal children. Bird and Krynauw (1953) reported a member of their family with Lindau's disease who lost the vision in one eye at the age of 2 , but examination of the fundus oculi was impossible because of a cataract in the lens. Two members of our family presented before puberty.

Case III9 developed symptoms of a cerebellar haemangioblastoma at the age of 8 , and 10 years later those of angiomatosis retinae.

Case IV8 at the age of 10 developed evidence of a tumour in the left petrous bone. At operation a cyst was found which contained altered blood. Although no tumour was seen it was presumed that an angioma was present. Brandt (1921) has described a similar case, a patient of von Hippel, who was shown to have angiomatosis retinae during life. At necropsy a walnutsized tumour was found, which was eroding the apex of the left petrous-temporal bone, and was in close relation to the third, fourth, fifth, and sixth cranial nerves. The tumour had a smooth surface and was fused with the dura. Tumours were also found in the left cerebellum and elsewhere. In one of Melmon and Rosen's cases (case III3) a haemangioblastoma of the cerebellum was found which extended to the dura, and was 'somewhat adherent' to the petrous portion of the temporal bone. Histological examination of this bone showed a separate lesion, namely, an haemangioma. In another of Melmon and Rosen's cases (case III17) a cerebellar haemangiogioblastoma was removed and an osteolytic lesion of the right parietal bone was seen on skull radiographs, slowly enlarging over six years. They suggested that this may also have been an haemangioma of bone. Vail (1958) reported a patient with angiomatosis retinae whose skull radiograph showed 'a circular defect about $1 \mathrm{~cm}$. in diameter located just to the right of the mid-line in the frontal bone. The defect communicates with the venous channel, which has no counterpart on the other side, which extends downward and slightly laterally across the frontal bone. This defect is the result of an unusually large venous channel, but it could be the result of a vascular tumour. The skull appears otherwise normal'. Eleven years later the skull radiograph was unchanged but Vail thought that in view of the combination of angiomatosis retinae with this appearance on the skull radiograph a diagnosis of Lindau's disease must be considered.

Since Lindau's disease is characterized by angiomata, the association with haemangioma of bone is likely to be more than just coincidental, and it seems reasonable to postulate that this is another manifestation of Lindau's disease.

In case IV8 the diagnosis of haemangioma of bone was not proved, but the circumstantial evidence for this diagnosis is strong. The explanation of the papilloedema in this case may be that the extradural cyst interfered with the circulation in the sigmoid and petrosal sinuses, producing a syndrome similar to that seen in otitic hydrocephalus.

Bickerstaff, Small, and Guest (1958) showed that meningiomata may present symptoms during pregnancy and remit after term. There is also in the literature one case of angiomatosis retinae presenting in pregnancy, described by Armstrong (1937), and there are 10 cases of cerebellar haemangioblastomata. Six of these were described by Robinson (1965), the others by Dandy (1928), Möller (1944), Duperrat (1945), and Scarcella, Allen, and Andy (1961). Möller's patient first presented with angiomatosis retinae. Twelve years later, during her second pregnancy, she developed symptoms of a cerebellar haemangioblastoma, including vomiting for four months. Three sisters in the present series suffered from vomiting during pregnancy. The excessive vomiting of pregnancy shown by case 
IV8 is particularly interesting. This appeared to have all the characteristics of hyperemesis gravidarum including stopping on both occasions when the second and third pregnancies were terminated. At the time no abnormal neurological signs were present, although the patient was subsequently found to have a small haemangioblastoma and cyst on the floor of the fourth ventricle.

\section{SUMMARY}

A family with Lindau's disease is described. Six members of four generations have been affected by intracranial lesions. One patient developed classical hyperemesis gravidarum during two pregnancies. One of her sisters first developed neurological symptoms during the puerperium. Two patients presented neurological symptoms before puberty.

For their encouragement and advice we wish to thank Professor R. W. Gilliatt, Mr. John Andrew, and Mr. J. R. Belcher; for permission to publish case histories we are indebted to Professor Brodie Hughes, Mr. Joe Pennybacker, Dr. Bruce Hendrick and Mr. D. W. Hill; and for their tireless energy Mrs. C. Postles and Miss J. Herbert.

\section{REFERENCES}

Armstrong, M. V. (1937). Angiomatosis retinae (von Hippel's disease, Lindau's disease) complicated by pregnancy. Amer. J. Obset. Gynec., 34, 494-496.

Bergstrand, H., Olivecrona, H., and Tönnis, W. (1936). Gefässmissbildungen und Gefässgeschwülste des Gehirns. Thieme, Leipzig.

Bickerstaff, E. R., Small, J. M., and Guest, I. A. (1958). The relapsing course of certain meningiomas in relation to pregnancy and menstruation. J. Neurol. Neurosurg. Psychiat., 21, 89-91.

Bird, A. V., and Krynauw, R. A. (1953). Lindau's disease in a South African family. Brit. J. Surg., 40, 433-437.

Borck, W. F., and Tönnis, W. (1955). Zur Differentialdiagnose infratentorieller Geschwulste. Fortschr. Neurol. Psychiat., $23,125-166$.

Brandt, R. (1921). Zur Frage der Angiomatosis retinae. Albrecht v. Graefes Arch. Ophthal., 106, 127-165.
Bray, P. T., and Davies, W. (1949). Spontaneous subarachnoid haemorrhage in infancy due to angioma of the cerebellum. Brit. med. J., 1, 481-482.

Christoferson, L. A., Gustafson, M. B., and Petersen, A. G. (1961). von Hippel-Lindau's disease. J. Amer. med. Ass., 178, 280-282.

Collins, E. Treacher (1894). Intra-ocular growths. I. Two cases, brother and sister, with peculiar vascular new growth, probably primarily retinal, affecting both eyes. Trans. ophthal. Soc. U.K., 14, 141-149.

Cramer, F., and Kimsey, W. (1952). The cerebellar hemangioblastomas. Review of fifty-three cases, with special reference to cerebellar cysts and the association of polycythemia. Arch. Neurol. Psychiat. (Chic.), 67, 237-252.

Dandy, W. E. (1928). Venous abnormalities and angiomas of the brain. Arch. Surg., 17, 715-793.

Duperrat, B. (1945). Tumeur cérébrales et grossesse. Presse mèd., 53, $118-119$.

Fuchs, E. (1882). Aneurysma arterio-venosum retinae. Arch. Augenheilk., 11, 440-444.

von Hippel, E. (1904). Uber eine sehr seltene Erkrankung der Netzhaut. Albrecht v. Graefes Arch. Ophthal. 59, 83-106.

Isfort, A., and Sunder-Plassmann, P. (1965). Klinik und Diagnostik der Lindautumoren. Dtsch. Z. Nervenheilk., 187, 548-565.

Jefferson, G. (1953). Discussion on the differential diagnosis of lesions of the posterior fossa. Proc. roy. Soc. Med., 46, 719-726.

Krayenbühl, H., and Yasargil, M. G. (1958). Das Kleinhirnhamangiom. Schweiz. med. Wschr., 88, 99-104.

Larson, C. A. (1957). Capillary angiomatosis of the central nervous system (Lindau's disease). Genetic aspects. Acta genet. (Basel), 7, 341-344.

Lindau, A. (1926). Studien über Kleinhirncysten. Acta path. microbiol. scand., suppl. no. 1.

Melmon, K. L., and Rosen, S. W. (1964). Lindau's disease. Review of the literature and study of a large kindred. Amer. J. Med., 36, 595-617.

Möller, H. U. (1944). Ophthalmic symptoms and heredity in cerebellar angioreticuloma. Acta psychiat. (Kbh.), 19, 275-292.

Nicol, A. A. McI. (1957). Lindau's Disease in five generations. Ann. hum. Genet., 22, 7-15.

Robinson, R. G. (1965). Aspects of the natural history of cerebellar haemangioblastomas. Acta neurol. scand., 41, 372-380.

Scarcella, G., Allen, M. B., and Andy, O. J. (1961). Vascular lesions of the postelior fossa during pregnancy. Amer. J. Obstet. Gynec., 82, 836-840.

Silver, M. L., and Hennigar, G. (1952). Cerebellar hemangioma (hemangioblastomas), a clinicopathological review of $\mathbf{4 0}$ cases. J. Neurosurg., 9, 484-494.

Stein, A. A., Schilp, A. O., and Whitfield, R. D. (1960). The histogenesis of hemangioblastoma of the brain. Ibid., 17, 751-761.

Vail, D. (1958). Angiomatosis retinae, 11 years after diathermy coagulation. Amer. J. Ophthal., 46, 525-534.

Yin Hsiao-Tung, and Chang Yuan-Ch'ang (1965). Familial angioreticulomas (Lindau's disease). Report of 11 cases in a single family. Chin. med. J., 84, 679-683.

Requests for reprints should be addressed to Dr. P. J. Bourdillon, 77 Addison Road, London, W.14. 